\title{
Automation and Fuzzy Control of a Manufacturing System
}

\author{
Zermane Hanane $^{1}$, Mouss Hayet ${ }^{2}$, Benaicha Sonia ${ }^{3}$ \\ Laboratory of Automation and Manufacturing \\ Industrial Engineering Department \\ University of Batna \\ Batna, Algeria \\ hananezermane@yahoo.fr \\ hayet_mouss@yahoo.fr \\ benaichas@yahoo.fr
}

\begin{abstract}
The automation of manufacturing systems is a major obligation to the developments because of exponential industrial equipment, and programming tools, so that growth needs and customer requirements. This automation is achieved in our work through the application programming tools from Siemens, which are PCS 7 (Process Control System) for industrial process control and FuzzyControl++ for fuzzy control. An industrial application is designed, developed and implemented in the cement factory in Ain-Touta (S.CIM.AT) located in the province of Batna, East of Algeria. Especially in the cement mill which gives the final product that is the cement.
\end{abstract}

Keywords-PLC; diagnostic; fuzzy logic; maintenance; expert systems.

\section{INTRODUCTION}

Automation systems from Siemens provide a safe and sustainable response to the ever-growing demands of modern machines and facilities [1]. The application of Siemens tools to automate our system, as a purely application is for the control of a cement mill, as well as the diagnosis and maintenance of various alarms generated during the course of three workshops, Power supply by clinker, cement mill and Storage.

We will use PLCs Siemens FuzzyControl++ to control the most important parameter tells the fineness of the cement, From a point of view process, fast dynamic response relative to the change in speed of the separator in the grinding process of cement can a fast, stable and good fineness of the product. We also control the temperature of the cement. Therefore, avoiding downtime during grinding, reducing the variations in the quality of products also reduced specific energy consumption. Control the cement mill, the operation stability and feeding by the clinker. Control and finesse, so far, the strategy based on measures provided manually offline.

The use of expert systems and fuzzy logic in our application is based on a model of fuzzy information. The latter according to Earl Cox [2], has a significantly higher computing power than a symbolic expert system, which provides parallel processing by nature, the ability to a high level of sets, rather than data after data, in addition, the ability to treat very accurately inaccurate information, and give results consistent with the data and rules.

\section{PROBLEMATIC}

The automation of production was one response to the changing industrial competitiveness. This automation was twofold: increasing the productivity of the technical system (cost reduction, reliability, availability, quality) and improving the safety of the operators directly, since the majority of them are far (and protected) where the transformation of the product.

The old control systems applied in cement showed several inadequacies, especially about the quality control of the product. The present trend is that the control system is based on Artificial Intelligence techniques such as fuzzy logic, expert systems, and neural networks.

The SCIMAT, our field of application is one of them. The expert system ECS (Expert Control \& Supervision) installed at the SCIMAT is the process control system. It is responsible for running equipment and diagnostic alarms. But the operator in case of alarms knows what to do or how to maintain it. It is his experience that guides or extensive training, as the system does not provide the maintenance task to perform.

Our goal is to apply fuzzy logic controllers separately, where the stopping of a controller does not require stopping the fuzzy control, even if the overall system instability. So ensure the fuzzy control, diagnosis of various alarms generated during process execution and maintenance.

The strongest point for this work is that our application based on fuzzy logic applied using FuzzyControl++ Siemens is not used in all Algerian cement, is not even tested.

\section{RELATED WORK}

Automated industrial systems are different from each other by the tools used. In different cement in the world, piping systems are made by the Danish company FLSmidth and Siemens. Cement plant in Ain Touta, the control system is ECS (Expert Control \& Supervision) developed by FLS and control system of the plant Ain El Kebira (SC.AEK) in Setif is designed by Siemens. The two plants currently do not have a system based on fuzzy logic. Although S.CIM.AT disposed of an old system based on fuzzy logic, but decommissioned for instability and several other issues, on one side. On the other 
hand, Siemens configuration tool called fuzzy logic FuzzyControl++, but is not applied in all Algerian cement.

\section{TOOLS USED}

SIMATIC PCS 7 is the automation platform common to all automation activities SIEMENS Process Industries. SIMATIC PCS 7 can meet the stringent requirements of the automation of production platforms offshore, units of production of pharmaceuticals, chemicals, refineries, cement plants and other industries. SIMATIC PCS 7 can globalize the function of automation that supports process control (continuous, discontinuous, batch production), the safety of people and property, recording status, while ensuring all driving consistency of automation tasks performed on the basis of the industrial Automation SIMATIC [3]. PCS 7 provides several tools for each task or type of programming. The diagram in Figure 1 shows the different tools used to create our application.

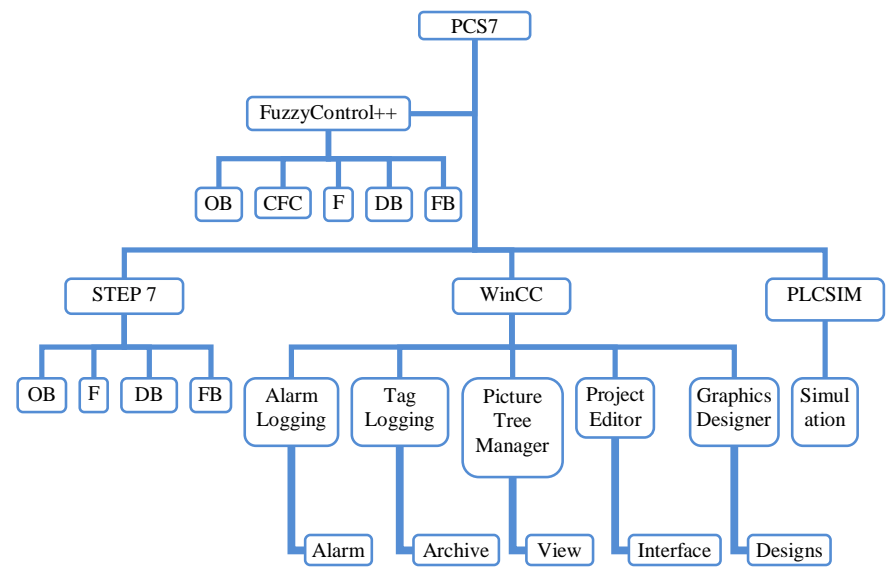

Figure 1. Tools used in our application

\section{A. FuzzyControl++}

The FuzzyControl++ configuration tool for the automation of technical processes enables the efficient development and configuration of Fuzzy systems. Empirical process know-how and verbalized knowledge by experience can be directly transformed into controllers, pattern identification, or decision logics.

Associated functions are also easy to configure with the help of the FuzzyControl++ tool. The rules are input either via a table or a matrix editor. Dynamic changes of the rules basis are identified immediately and, if no rule should be applicable, a value previously prescribed for each output will be used. The inference and defuzzification method used by FuzzyControl++ is the well-known Takagi-Sugeno method.

FuzzyControl++ can execute on SIMATIC S7 PLCs, the SIMATIC PCS7 process control system and the SIMATIC WinCC SCADA system and provides special function blocks and image blocks. SIMATC WinCC links the configured Fuzzy systems as smart objects with the help of an OLL. The Fuzzy systems are configured and generated by means of a configuration tool. The runtime software will process the systems during normal operation. [4]

\section{B. WinCC}

Siemens software for process control monitoring, it is a:

- Graphics system: display and operator control of the process pictures.

- Trend system: analysing the process.

- Message system: process diagnostics.

- Logging system: documenting the process.

- Archive system: storage and display of process values, messages and logs. [5]

C. Step 7

STEP 7 is the standard software package used for configuring and programming SIMATIC programmable logic controllers. It is a part of the SIMATIC Siemens industry software.

- Based on several types of programming: Flow chart, Contact List, SCL, Grafcet...

- Expandable with applications offered by the software industry SIMATIC.

- Calculation of functional modules and communication modules.

- Data transfer ordered by event using communication blocks and function blocks.

- Configuring Connections. [6]

\section{INDUSTRIAL APPLICATION}

\section{A. Cement plant}

The raw material comes from the career is crushed in a raw mill to have a raw meal. This last step requires a clinkering in the oven, under ideal conditions, this clinker is then ground with stored additions and gypsum in another mill gives us the final product, which is cement. The workshop involved in our application is the cement mill. Figure 2 includes all workshops in the cement factory plant.

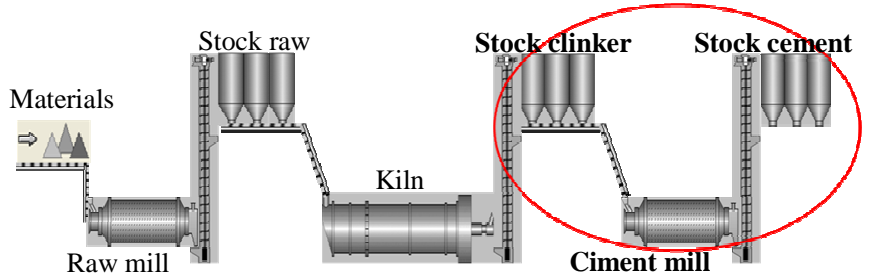

Figure 2. Cement factory plant

The workshop grinding cement is composed of three main parts, food mill by clinker, cement mill and silos.

\section{B. Sequence starting}

Starting equipment is ordered by a sequence of latest equipment to the first to ensure the availability of different motors, pumps or valves, and none of them had any problems, mechanical, electrical or other. Equipments were associated by interlocks and conditions start. 
Three types of interlocks corresponds equipment, locks walk (walking conditions or starting equipment), safety interlocks (equipment can be turned on, but some time can cause problems with the system turn to him) and interlocks protection (protection measures are equipment itself, as example the oil level, temperature, pressure ...). The chart in Figure 3 shows the startup sequence and interlocks associated with any equipment.

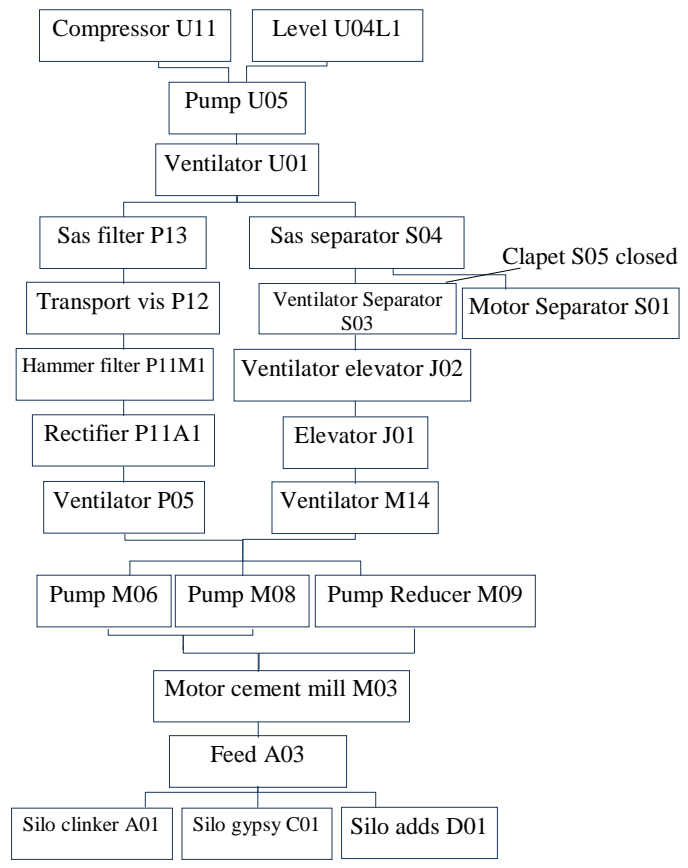

Figure 3. Sequence starting

\section{INDUSTRIAL REALISATION}

The application carried in the S.CIM.AT is the result of a training of eight months. This work is called, SEF-DIAGMA (System Expert Flou pour Diagnostic and Maintenance). The application used to automate the system by fuzzy control, diagnostics and maintenance of various alarms generated, avoiding unnecessary stops, energy consumption and increased production.

To explain our system, we will follow the boot sequence for devices. User interfaces are called operator stations. The first station will appear to the general interface operator is shown in Figure 4. Where the operator can't access to any shop, and also switch between different operator stations.

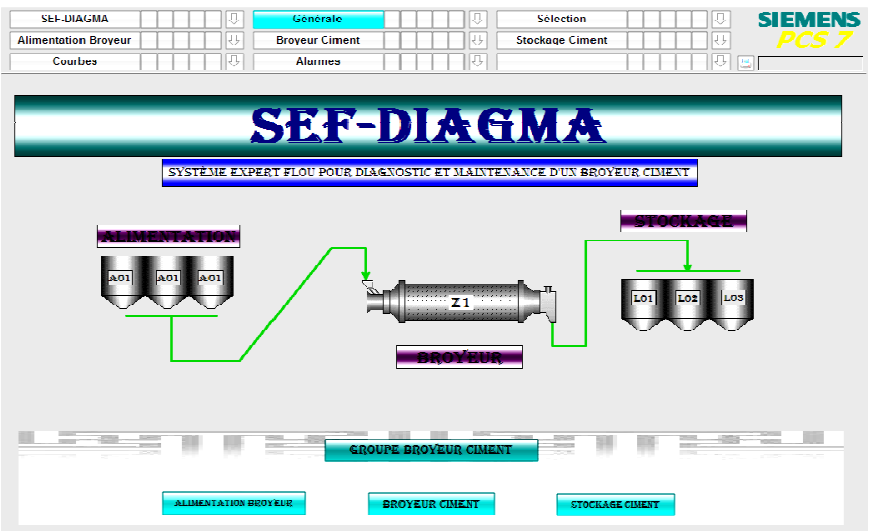

Figure 4. Interface générale

All views (operator station) that will be presented are realized by the WinCC Graphics Designer (Windows Control Center).

\section{A. Equipments selection and workshop starting}

1) Equipement selection :

Equipment selection is performed by selecting the groups, where each group contains a number of devices arranged according to the starting sequence. The start of the group means starting equipment included. Figure 5 shows the station operator for the selection of equipment, starting and stopping of the workshop.

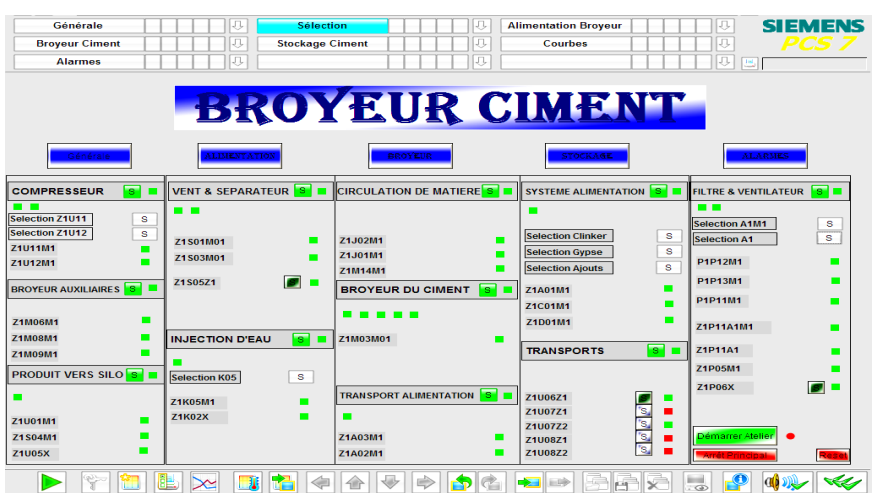

Figure 5. Equipments Selection

In some groups, if the equipment is redundant or not required. The choice of starting the equipment is selected by a separated button which corresponding.

\section{2) Alarms and acceptation of the starting program}

In case of a malfunction or shutdown of equipment, its color is red, it can be an alarm to the operator that the equipment must not start or maintained if it is already running. If no alarm is triggered, the workshop starts in good condition. Several operating conditions should be checked to ensure that the sequence starts without stopping. These conditions concern the filters, the maximum level of U04 hopper, feeders' clinker and other conditions, to ensure the start of the workshop. Block acceptance of the program when execution is shown schematically in Figure 6. 


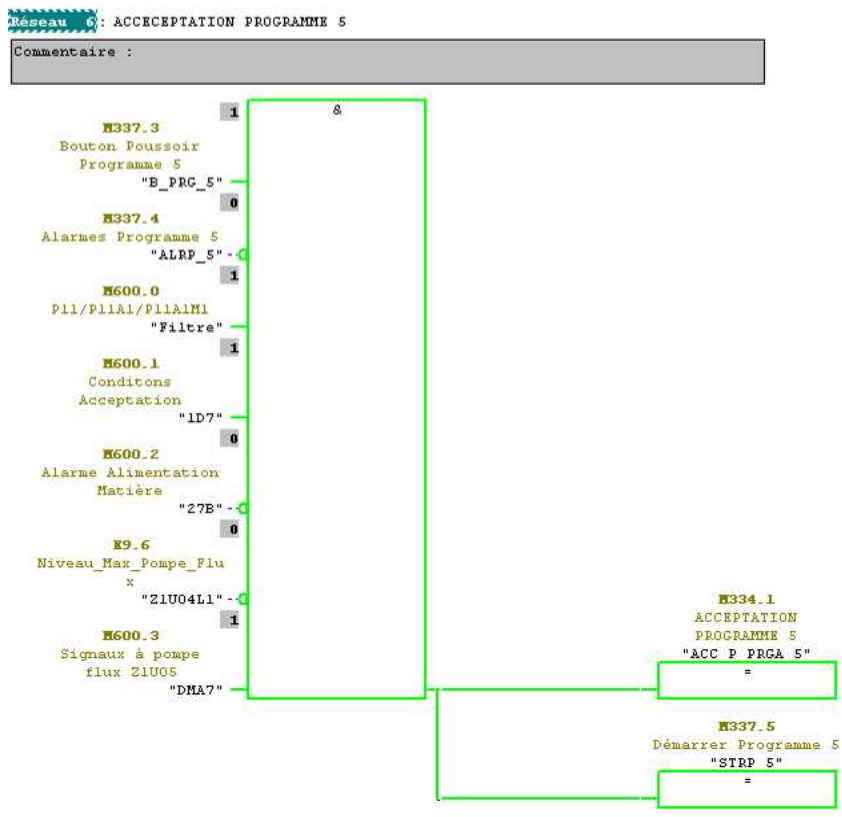

Figure 6. Starting acceptation

\section{B. Cement storage}

The first workshop is to start cement storage, this is to ensure the availability of elevators that will receive and store the cement. The workshop consists of three silos; each has valves for opening and closing the aeroglissiere. By clicking on the button (select), or click on the button (deselect) the operator can specify the empty silo or less percentage for storing cement. Figure 7 shows the workshop storage of cement.

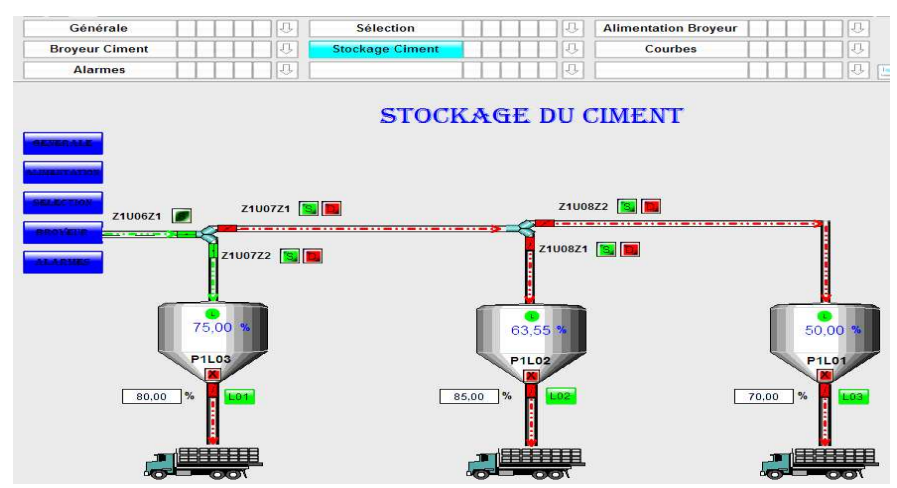

Figure 7. Cement Storage

In the case of a max level, an alarm is triggered to alert the operator to change the silo, and the system must stop the cement mill in the case of three alarms max.

\section{Cement mill}

\section{1) Cement mill :}

The grinding system contains four main parts, the cement mill (M01), lift (J01), the separator (S01) and electro-filter (P11). Figure 8 shows the grinding of cement. The system is fully automated, the boot is guaranteed, and in case of a shutdown of equipment, equipment that precedes it in the sequence stops after a period of time very specific.

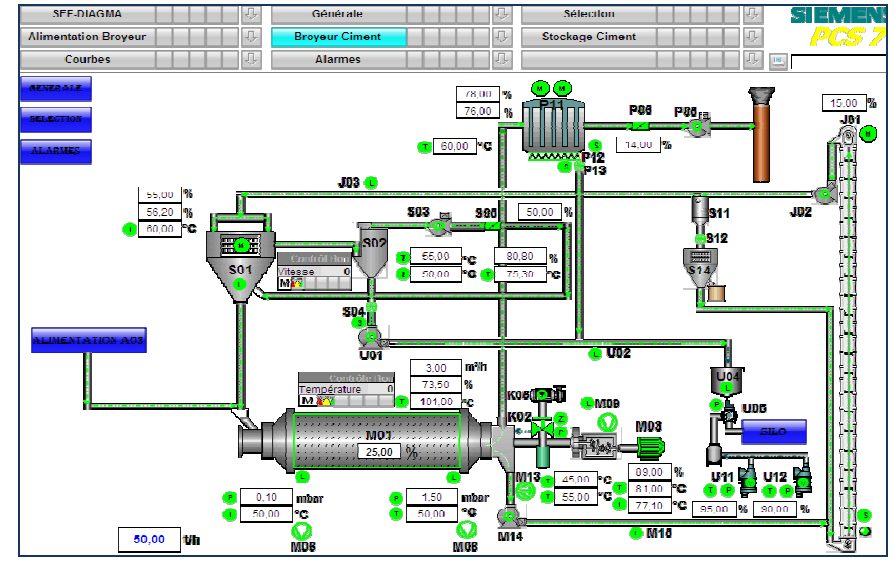

Figure 8. Cement mill

The grinding plant contains two fuzzy controllers, the control of speed of the separator and the temperature at the outlet of the mill. These two fuzzy controllers are designed using FuzzyControl++.

2) Fuzzy regulator:

The action of opening the valve depends to mill outlet temperature. The range of the degree of temperature is between $110{ }^{\circ} \mathrm{C}$ and $150{ }^{\circ} \mathrm{C}$, but for security reasons we have limited the degree to $125^{\circ} \mathrm{C}$, it must not be lower than $110^{\circ} \mathrm{C}$ to ensure the quality of cement, Figure 9 shows the properties of the input "temperature" of the fuzzy controller.

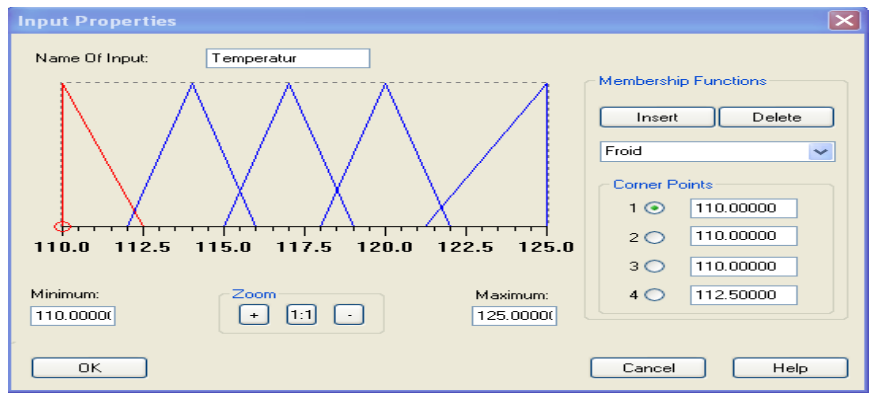

Figure 9. Fuzzy input

The output of the fuzzy controller is the percentage of opening of the valve, from $0 \%$ to $100 \%$. If regulator in manual mode, the operator should provides directly the percentage of opening of the valve. Figure 10 shows the output "valve" of fuzzy controller.

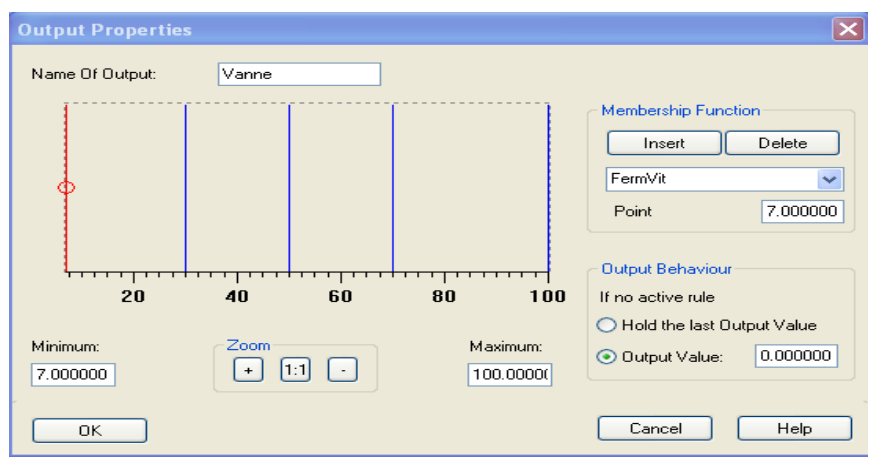

Figure 10. Fuzzy output 
To adjust of the temperature at the outlet mill, using the valve $\mathrm{K} 02$ by injecting water. If the temperature is $>=125{ }^{\circ} \mathrm{C}$ open the valve, and if the temperature is $<=110{ }^{\circ} \mathrm{C}$ close the valve. This is ensured by a set of fuzzy rules base showed in Figure 11.

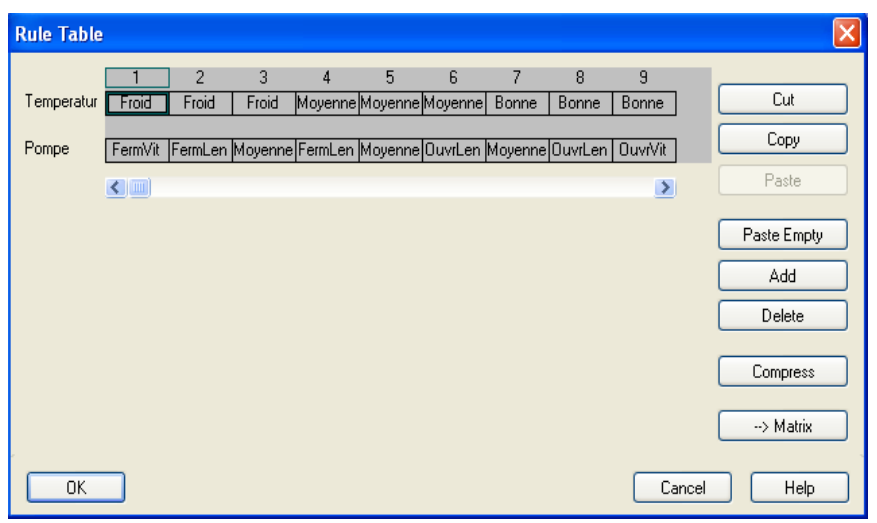

Figure 11. Fuzzy rule base

Control loop of the fuzzy controller in Figure 12 showing the opening action of the valve according to the temperature change. This regulation ensures continuous fuzzy control to treat all possible cases.

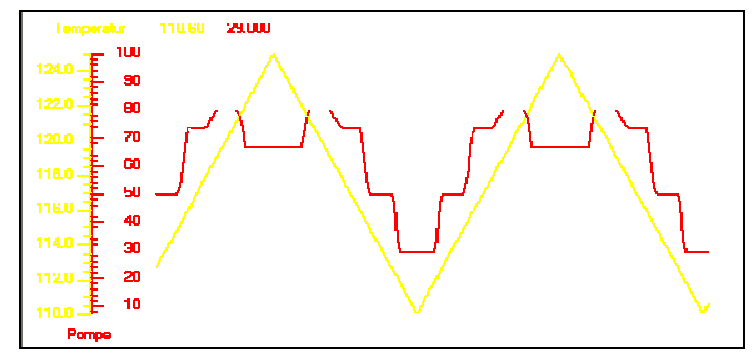

Figure 12. Fuzzy regulation trend

FuzzyControl ++ must be connected to WinCC to load the fuzzy rule base, using CFC-20K blocks. All data controller is charged with around a block of data (DB31) then loaded into WinCC. In Figure 13 we can see this connection, number of inputs and outputs and the state of loading data.

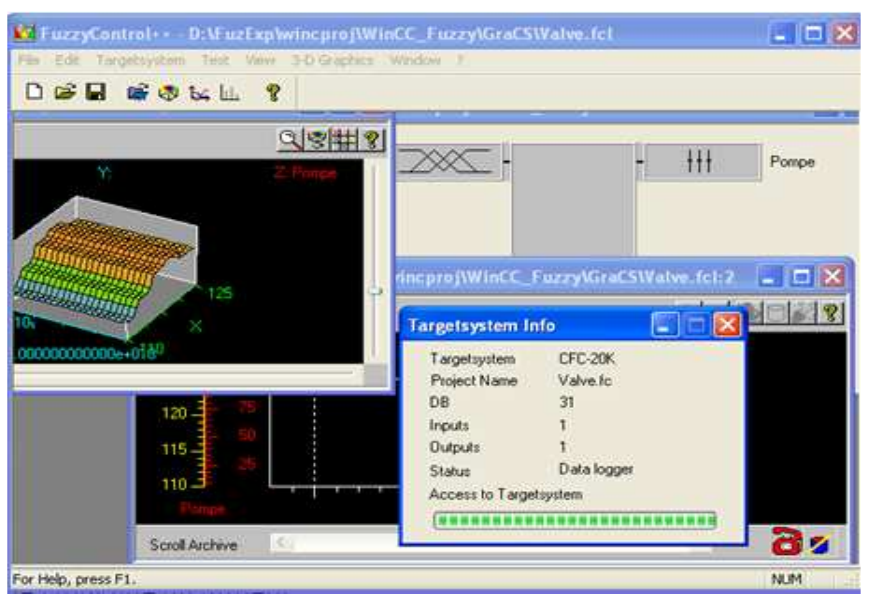

Figure 13. Fuzzy base rules laoded in the PLC
3) Fuzzy regulation in operateur station

By clicking the icon fuzzy controller

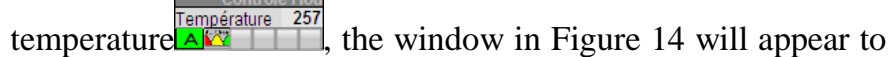
see the values of temperature (input1) and the percentage of valve opening (output1). The fuzzy rule base is loaded in the file "valve.fcl".

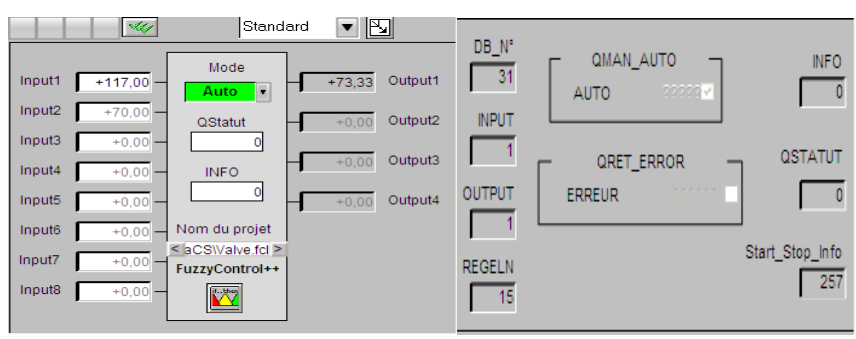

Figure 14. Fuzzy controller for temperature in station operator

The operator can change the mode, either automatic or manual. From which it can enter the percentage of valve opening directly.

\section{CEMENT MILL FEED}

The last step in the process is the grinding supply of the cement mill by clinker; the latter is the product of the firing of the raw meal in the kiln. Upon exiting the oven, the clinker must be cooled and then stored in the feeders. The clinker is transported by the transport belt (A01, A02 and A03). The supply of cement mill is composed of three elements, the clinker with $80 \%$ of the total diet, gypsum of $08 \%$ and additions by $12 \%$. Each one component is in a different silo. Figure 15 shows the feeders of cement mill.

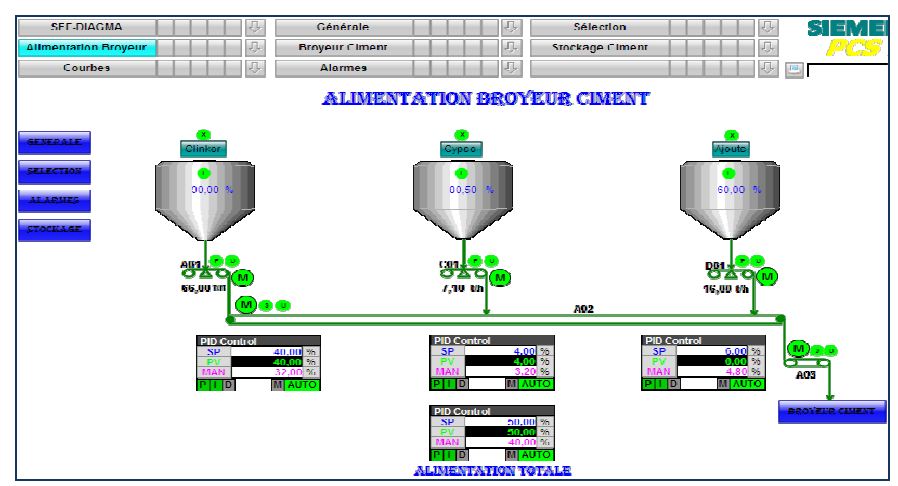

Figure 15. Cement mill feed

Regulating the supply is made by a cascade controller. The set point is the total diet. This set point is divided into three set points. The first relates to the clinker, the second for gypsum and the third for additions. Gypsum must not exceed $10 \%$ of the set point; the sum of the three percentages must not exceed $100 \%$.

\section{ALARMS DiagNOSTIC AND MAINTENANCE}

In the operator station, multiple alarms occur during the course of the workshop grinding. In food, cement mill or storage. And each occurrence of an alarm is displayed a maintenance action to be performed, where the operator must judge this action experience. For example, in Figure 16, an 
alarm indicating that the output pressure of the mill is high. This alarm generates stop the mill and then lift the separator, and the servo continuous if the alarm is not maintained and may be stopping any workshop.

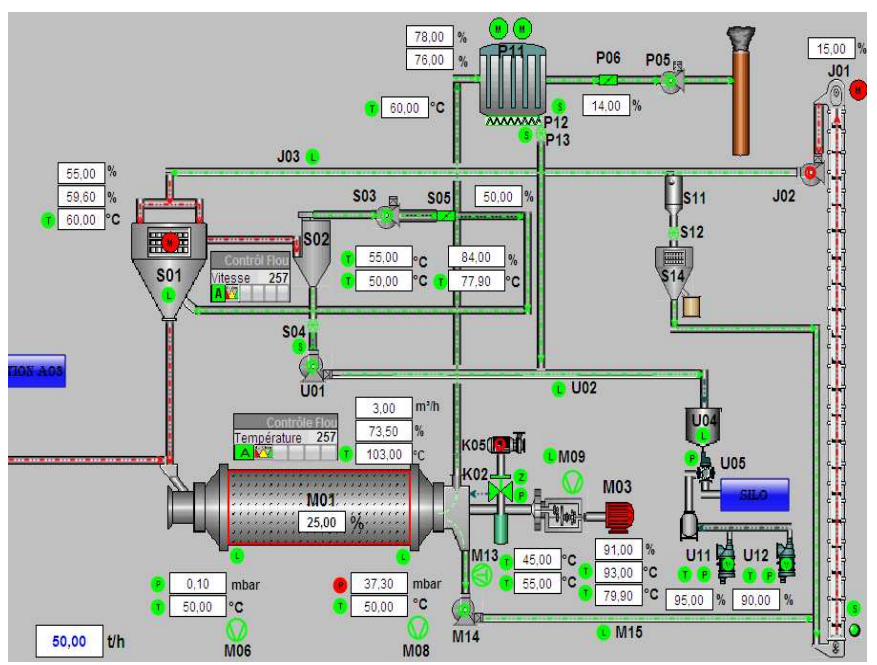

Figure 16. Cement mill if an alarm occur

The alarm is displayed in the top bar of the view and also appears in the alarm table.

Alarms are created in WinCC Alarm Logging, several types of alarms can occur among them, system alarms and process alarms. Each color indicates a type of alarms or a level (high "red" means "orange" low "green"), response "purple", or other type according to the diversity of alarms. Figure 17 illustrates some alarms and maintenance carried out.

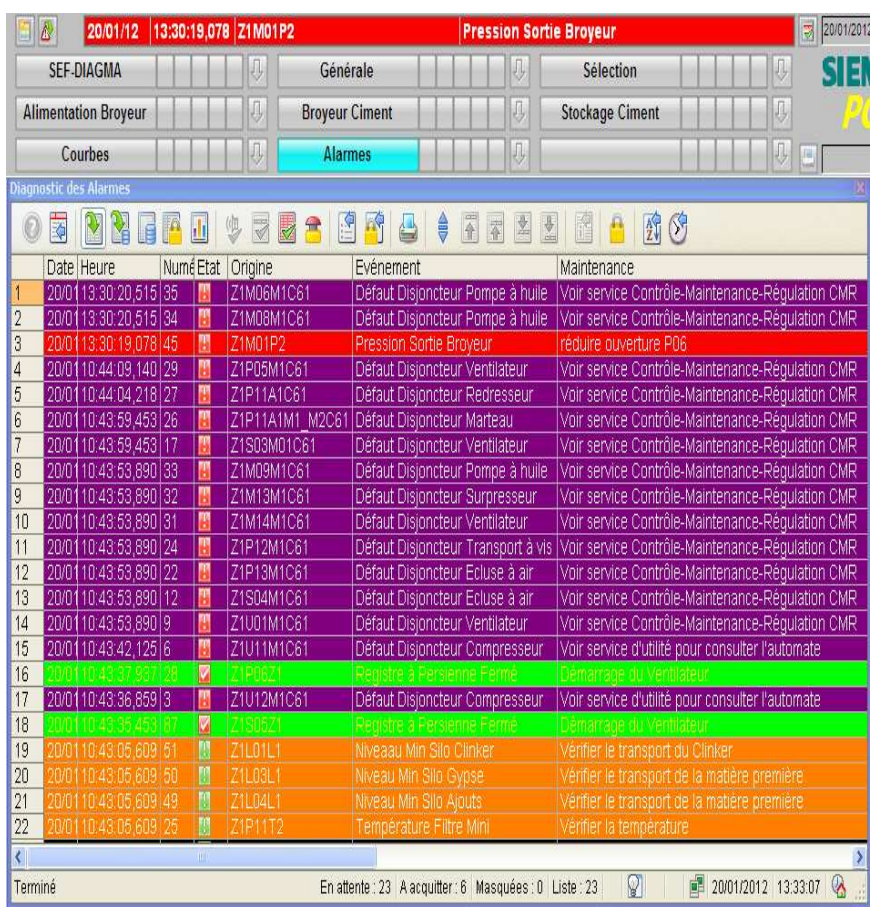

Figure 17. Alarms Table

On the Alarms table, the operator can acknowledge an alarm (an alarm ignore as not to interrupt the system to maintain) or more alarms. But the system saves a history of all alarms for reasons of preventive maintenance. [7]

\section{CONCLUSION}

The application of Artificial Intelligence techniques in industry is often difficult or technical side of the program, either in the quality of the materials on this application. Cement Ain Touta SCIMAT is very old, where the application of fuzzy logic requires highly efficient and advanced sensors.

Our application is based on the technique of fuzzy logic applied using the tool FuzzyControl ++ Siemens is not used in all Algerian cement, hence the creation of SEF-DIAGMA, a new expert system blur for monitoring, diagnosis and maintenance, carried out within the SCIMAT is the development of an approach to diagnosis and maintenance, as well as fuzzy control, to ensure the overall automation system studied.

The system helps the operator to diagnose alarms and also their maintenance. And fuzzy control is provided by the fuzzy controllers, where even in case of unavailability of one; the other can continue its work. Therefore, the fuzzy control continuously ensures consistent quality of the finished product. On the other hand, the fuzzy controllers have a greater effect than ordinary regulators, especially for time control and stabilization system.

\section{REFERENCES}

[1] http://www.automation.siemens.com/automation/ch/fr/technique-dautomatisation/systemes-d-automatisation-et-de-controle/systemesindustriels-d-automatisation-simatic/Seiten/Default.aspx

[2] Cox, Earl. La Logique Floue Pour les affaires et l'industrie. [trad.] Maurice Clerc. Paris : Internationnal Thomson Publishing, 1997.

[3] https://www.swe.siemens.com/france/web/fr/ad/produits/automatisation/ systeme/SIMATIC_PCS7/Pages/simatic_pcs.aspx.

[4] http://support.automation.siemens.com/WW/llisapi.dll?func=cslib.csinfo \&objid=18791728\&nodeid0=10805418\&caller=view\&switchLang (FuzzyControl++).

[5] Siemens. SIMATIC. Système de conduite de processus PCS 7. OS Conduite du process (V7.1). Instructions de service. Allemagne : Siemens, 2009. A5E02122499-01.

[6] Siemens, SIMATIC. Programmer avec STEP 7. Manuel. Allemagne : Siemens, 2006. A5E00706945-01.

[7] Zermane Hanane, Les systèmes experts et la logique floue dans le domaine du diagnostic et de la maintenance, thèse de magistère, http://theses.univ-batna.dz/, 2011.

\section{Creative Commons Attribution License 4.0 (Attribution 4.0 International, CC BY 4.0)}

This article is published under the terms of the Creative Commons Attribution License 4.0

https://creativecommons.org/licenses/by/4.0/deed.en_US 